\title{
Article \\ The Isocyanurate-Carbamate-Bridged Hybrid Mesoporous Organosilica: An Exceptional Anchor for Pd Nanoparticles and a Unique Catalyst for Nitroaromatics Reduction
}

\author{
Ali Zebardasti ${ }^{1}$, Mohammad G. Dekamin ${ }^{1, * \mathbb{D}}$ and Esmail Doustkhah ${ }^{2, * \mathbb{C}}$ \\ 1 Pharmaceutical and Heterocyclic Compounds Research Laboratory, Department of Chemistry, \\ Iran University of Science and Technology, Tehran 1684613114, Iran; zebardasti@nano.ir \\ 2 International Center for Materials Nanoarchitechtonics (MANA), National Institute for Materials \\ Science (NIMS), 1-1 Namiki, Tsukuba, Ibaraki 305-0044, Japan \\ * Correspondence: mdekamin@iust.ac.ir (M.G.D.); Esmaildostkhah@gmail.com (E.D.)
}

check for updates

Citation: Zebardasti, A.;

Dekamin, M.G.; Doustkhah, E. The Isocyanurate-Carbamate-Bridged

Hybrid Mesoporous Organosilica: An

Exceptional Anchor for Pd

Nanoparticles and a Unique Catalyst for Nitroaromatics Reduction.

Catalysts 2021, 11, 621. https://

doi.org/10.3390/catal11050621

Academic Editor: Piotr Kuśtrowski

Received: 27 April 2021

Accepted: 9 May 2021

Published: 12 May 2021

Publisher's Note: MDPI stays neutral with regard to jurisdictional claims in published maps and institutional affiliations.

Copyright: (c) 2021 by the authors. Licensee MDPI, Basel, Switzerland. This article is an open access article distributed under the terms and conditions of the Creative Commons Attribution (CC BY) license (https:// creativecommons.org/licenses/by/ $4.0 /)$.

\begin{abstract}
Hybridisation of mesoporous organosilicas (MO) to reinforce the surface capability in adsorption and stabilisation of noble metal nanoparticles is of great attention in generating/supporting noble metal within their matrices and transforming them into efficient heterogeneous catalysts. Here, we used a unique hybrid of organic-inorganic mesoporous silica in which pore profile pattern was similar to the well-known mesoporous silica, SBA-15 for catalysis. This hybrid mesoporous organosilica was further engaged as a support in the synthesis and stabilisation of Pd nanoparticles on its surface, and then, the obtained Pd-supported MO was employed as a heterogeneous green catalyst in the conversion of aqueous $p$-nitrophenol (PNP) to $p$-aminophenol (PAP) at room temperature with efficient recyclability.
\end{abstract}

Keywords: hybrid mesoporous silica; Pd nanoparticles; $p$-nitrophenol; reduction; heterogeneous catalyst; PMO

\section{Introduction}

Nanoporous silicas modified/constructed by organosiloxanes (MO) [1-5] are a class of hybrid silica-based materials that are widely used in the diverse variety of applications including catalysis [6,7], microextraction [8], water treatment [9], molecular recognition [10], photocatalysis [11], optical thermometry [12], sensors [13,14], and $\mathrm{CO}_{2}$ capture $[15,16]$. These materials can be synthesised by condensation of various organosiloxane precursors and usually have amorphous structures but with ordered/disordered pore channels. Some of these materials can have microporosity alongside the mesoporosity, which can increase the surface area and subsequently the efficiency of the material in the applications $[17,18]$. Furthermore, in some cases, these materials are promising to metal-organic-frameworks in viewpoint of porosity and stability $[5,19]$. Since these materials are synthetic, there should be a synthetic bottom-up strategy for reaching to such materials in which the presence of template (mostly a soft template), e.g., F127 and P123, is inevitable [4,20,21].

When an organosiloxane bridge with significant flexibility is being used in a $\mathrm{MO}^{\prime} \mathrm{s}$ structure, the organosiloxane bridge should co-condense with a silica source (e.g., tetraethyl orthosilicate (TEOS)) to generate a uniform and robust mesoporous structure from viewpoint of mechanical toughness and porosity [4]. Several advantages belong to MOs, which cannot be found in conventional hybrid mesoporous silica materials [22]. For instance, in MOs, depending on the type of bridge, a higher ratio of organosilica can be embedded in the structure of MO, while in the case of conventional mesopores, e.g., SBA-15, it is an overwhelming process to functionalise with organosiloxane precursors in high ratio that usually deals with pore blocking or unsuccessful process [23]. In MOs, the mass transfer in pores for guest molecules is more efficient and also more promising than conventional 
hybrid silica mesopores $[12,24,25]$. This efficiency in transfer of molecules improves the lifetime of the $\mathrm{MO}$ and catalytic activity through minimizing the pore-blocking possibility by guest molecules [26-28]. This is because the organosilica motif of conventional mesoporous silicas stay on the external surface of pore channels, while in MOs, it can be embedded in the pore wall [29].

The use of mesoporous silica materials is of great importance among the candidates for synthesis of heterogeneous catalysts [30-34]. These materials can provide excellent heterogeneous surface for immobilisation of catalytically active metal species for various reactions, such as cross coupling and reduction reactions [35-39]. These materials can also provide an excelling recyclability by tuning the ratio and type of the organosilica. $\mathrm{Pd}$, among the noble metals, has played a pivotal role in the catalysis since $\mathrm{Pd}$ is an active catalytic species for a broad domain of reactions, e.g., cross-coupling [40,41], oxidation [42], reduction [6], and dehydrogenation $[17,43]$. Here, we integrated the isocyanurate and carbamate functional groups in the MO and used it for supporting of $\mathrm{Pd}$ nanoparticles. This was further employed as a heterogeneous green catalyst for the aqueous room temperature reduction of PNP to PAP.

\section{Results and Discussion}

\subsection{Synthesis and the Characterisation of the Catalyst}

We here synthesised a silica porous material by co-condensation method, where the organic and inorganic are homogeneously mixed and dissolved into a new material. Since this hybrid mesoporous silica material (MO-ISO) was obtained by co-condensation of a synthetic organosiloxane, we developed a facile one-step solvent-free approach to synthesise the organosiloxane precursor in our laboratory, as represented in Figure 1, and we further used it for immobilisation of Pd nanoparticles. These Pd nanoparticles were primarily obtained by adsorption of $\mathrm{Pd}^{2+}$ ions on MO-ISO and eventual reduction of them with $\mathrm{NaBH}_{4}$ at room temperature.

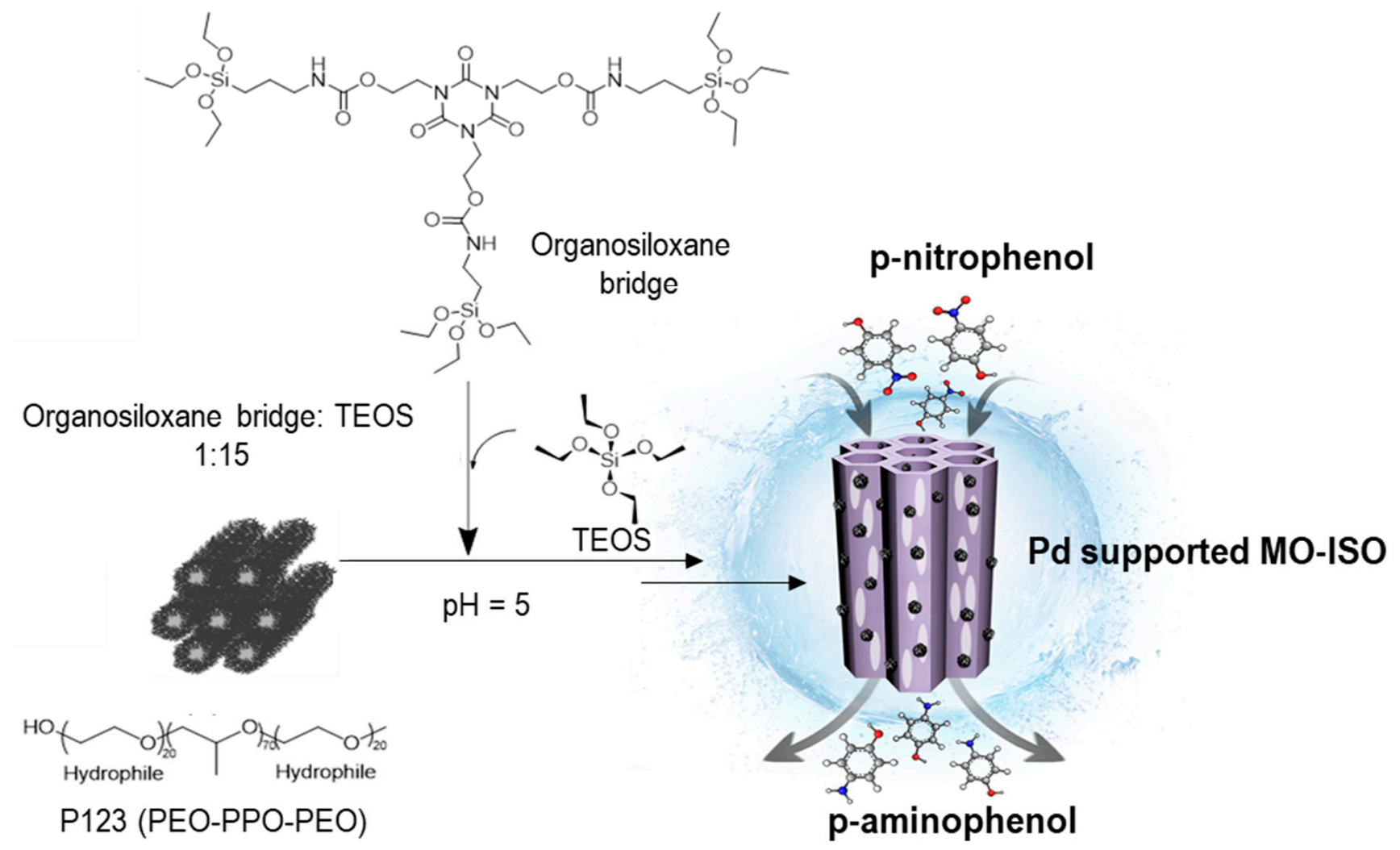

Figure 1. Schematic representation of Pd@MO-ISO synthesis. 
We previously proved the successful synthesis of this organosiloxane bridge by various techniques such as ${ }^{1} \mathrm{H}$ - and ${ }^{13} \mathrm{C}-\mathrm{NMR}$, FTIR, and mass spectroscopy, which all have been discussed in the literature [16]. We used this isocyanurate-carbamate organosiloxane bridge (ISO bridge) to synthesise the mesoporous organosilica (MO-ISO) with a high surface area and mechanically stable properties. Since in the previous study, we showed that the ratio of TEOS to organosiloxane precursor has a critical effect on the surface area and morphology, we selected the molar ratio of 1:15 (organosiloxane to TEOS, respectively). For studying the surface area, the $\mathrm{N}_{2}$ adsorption-desorption isotherms of the synthesised MO-ISO were evaluated and represented in Figure 2. Accordingly, the surface area is obtained around $697 \mathrm{~m}^{2} \cdot \mathrm{g}^{-1}$ with type IV isotherm and the average pore size is $6.2 \mathrm{~nm}$. Going further, the Pd-supported MO-ISO (Pd@MO-ISO) has exhibited a relative loss in the surface area $\left(389 \mathrm{~m}^{2} \cdot \mathrm{g}^{-1}\right)$, however, the surface area is still high, compared to other porous materials (Figure 2). This decrease in the surface area can be attributed to the relative occupancy of the pore space through the Pd nanoparticles.
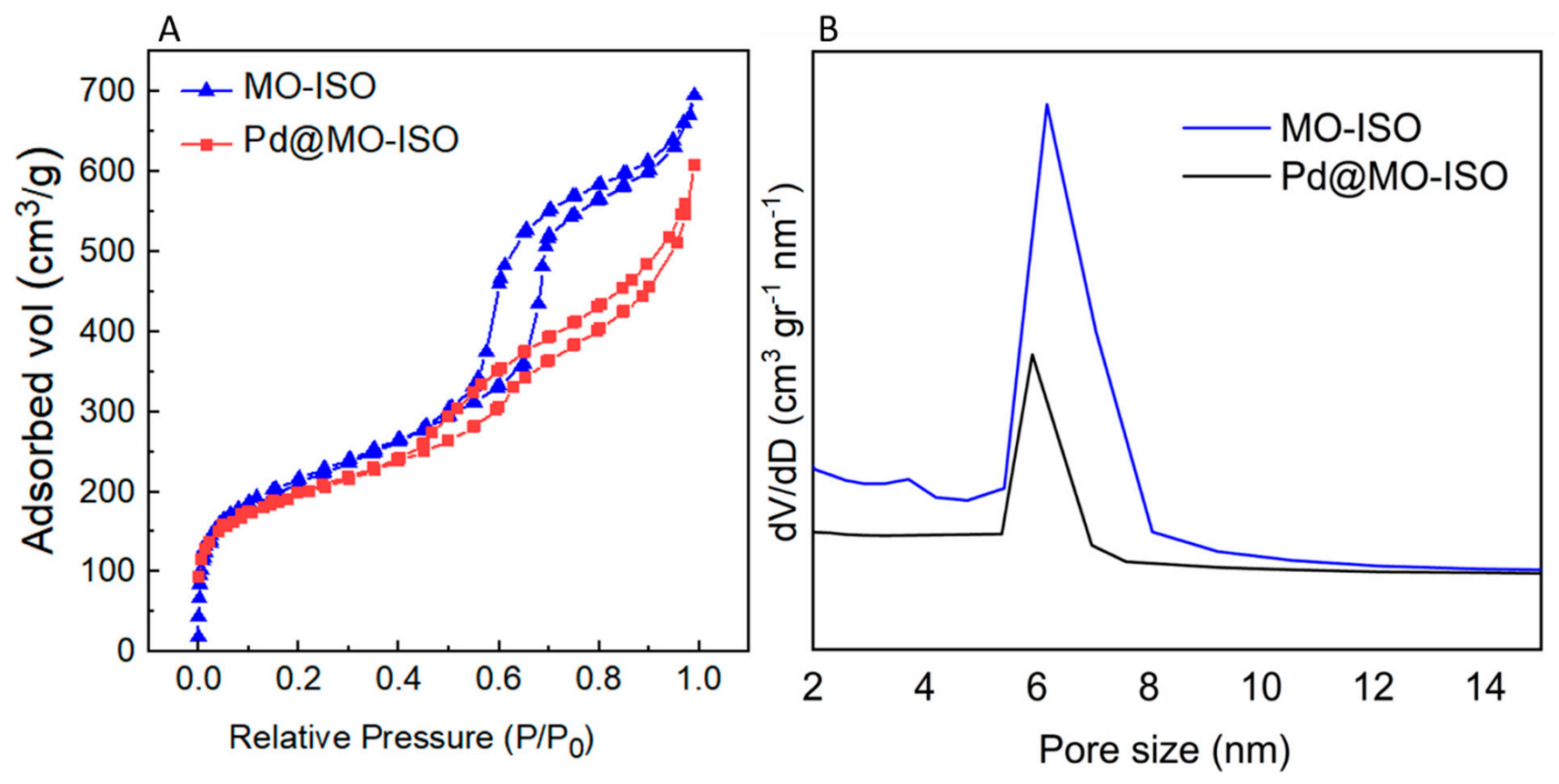

Figure 2. (A) $\mathrm{N}_{2}$ adsorption-desorption isotherms and (B) BJH plots of MO-ISO and Pd@MO-ISO.

The FTIR spectrum for 1,3,5-tris(2-hydroxyethyl)-1,3,5-triazinane-2,4,6-trione (THEIC), the heterocyclic starting material of ISO bridge, was compared with the FTIR spectrum of the MO-ISO to see if the main structure of ISO has undergone any change (Figure 3). This can be judged by the existence of two sharp bands at 1467 and $1700 \mathrm{~cm}^{-1}$ related to the stretching vibrations of the isocyanurate carbonyl located in the ring. A small shift in this regard can be observed to these band positions, which can be attributed to the change in the intermolecular hydrogen bondings in the pure form and when embedded in the MO structure. Some peaks in the range of $2900-3000 \mathrm{~cm}^{-1}$ are also related to the aliphatic chains (ethylene) of the ISO bridge.

Since the generated carbamate groups are sensitive to the acidic and basic media, we carefully examined the appeared two peaks in the ${ }^{13} \mathrm{C}-\mathrm{NMR}$ spectrum of MO-ISO related to the carbonyls (one to carbamate (156 ppm) and another to the isocyanurate (148 ppm)), which can confirm that the ISO bridge has been retained intact in the structure [16]. 


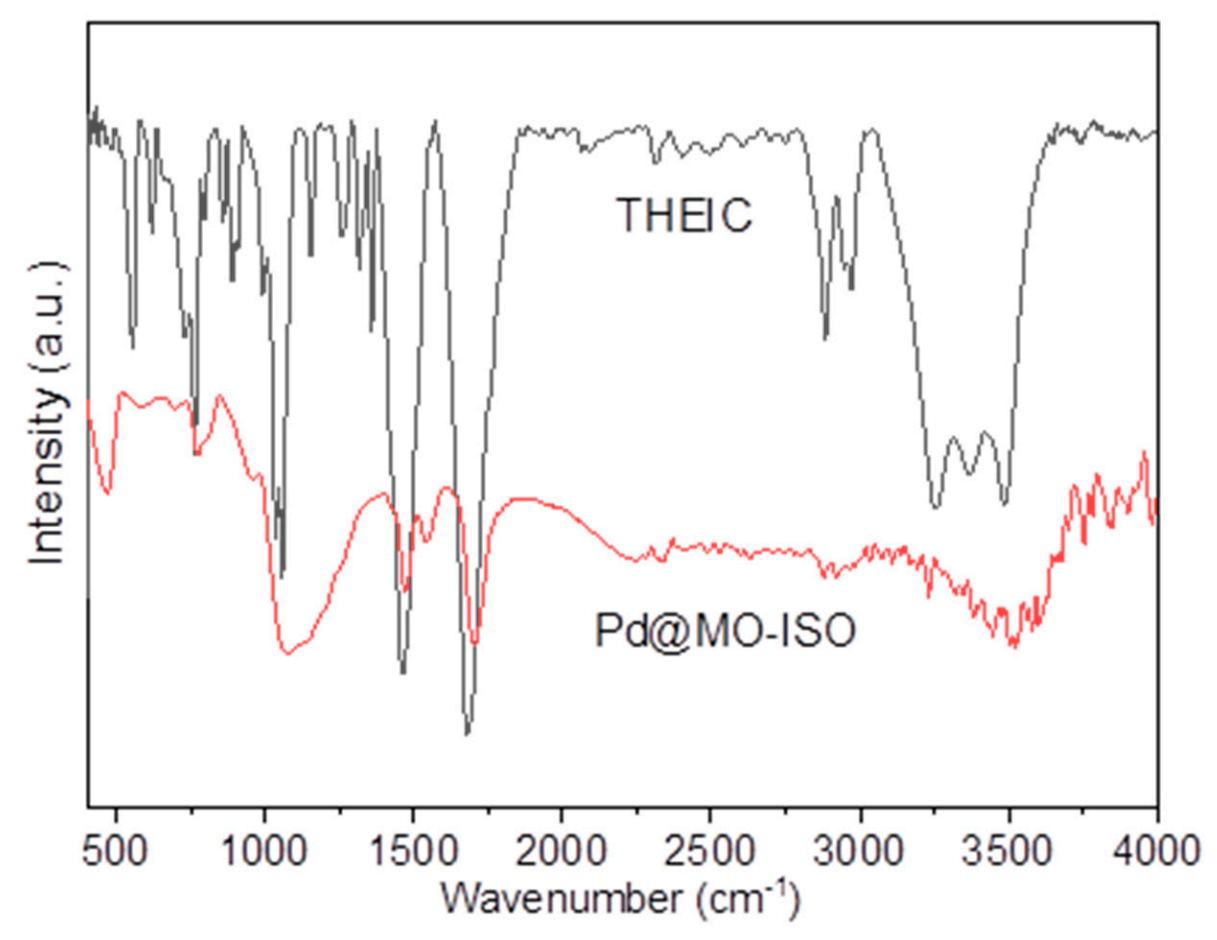

Figure 3. ATR-FTIR spectra of THEIC and Pd@MO-ISO.

SEM micrographs of MO-ISO morphology exhibits micro-sized particles, showing that the mesopores are assembled and aggregated into the large particles (Figure 4A). Furthermore, high-angle annular dark-field scanning transmission electron microscopy (HAADF-STEM) image of MO-ISO confirms the presence of Pd nanoparticles distributed in the MO-ISO's matrix. Note that the Pd nanoparticles are with lighter colour, since the more the condense matter, the lighter the appearance it takes in HAADF-STEM image (Figure 4B). Looking at the TEM image of MO-ISO reveals that the structure of MO-ISO is hexagonally ordered with uniform pore size distribution (Figure 4C). Moreover, the Pd-supported MO-ISO confirms the presence of Pd nanoparticles formed on the MO-ISO (Figure 4D). The calculated sizes of Pd nanoparticles according to the TEM and HAADF-STEM images are found to be $\sim 12.9 \mathrm{~nm}$ (See inset Figure 4D).

In addition, we studied the Pd nanoparticles and the MO-ISO structure through elemental TEM-mapping and TEM-based electron-dispersive spectroscopy (EDS). We confirmed the supporting of Pd nanoparticles in MO-ISO structure by scanning the related elements such as $\mathrm{O}, \mathrm{N}, \mathrm{C}$, and $\mathrm{Si}$ through TEM-mapping. This is illustrated in Figure 5A. Figure 5B also shows the TEM-EDS spectra of Pd@MO-ISO. This analysis confirms the presence of $\mathrm{Pd}$ element in the structure as well as other critical elements, e.g., $\mathrm{C}, \mathrm{N}$, and $\mathrm{Si}$.

\subsection{Catalytic Test}

Further, we tested the catalytic activity of Pd@MO-ISO in the reduction of nitroaromatics by testing PNP in the aqueous media at room temperature. In this regard, we used sodium borohydride $\left(\mathrm{NaBH}_{4}\right)$ as reducing agent and $\mathrm{H}_{2} \mathrm{O}$ as a green solvent. The catalyst, Pd@MO-ISO, was used in different amounts to see which ratio of Pd to the reactant, PNP, has the higher TON. Accordingly, the results indicated that $5 \mathrm{mg}$ catalyst in $3 \mathrm{mM}$ PNP solution $(40 \mathrm{~mL})$ has a higher activity in terms of Turn Over Number (TON). TON was obtained by following formula: 


$$
\mathrm{TON}=\frac{\text { generated product }(\mathrm{mmol})}{\text { active sites of the catalyst }(\mathrm{mmol})},
$$

where the TON value was obtained as 125 for the PNP reduction through $5 \mathrm{mg}$ Pd@MO-ISO (with $2 \mathrm{wt} \%$ of Pd content) and $0.12 \mathrm{mmol}$ PAP. Note that we assigned the active sites of the catalyst to entire number of Pd atoms in the structure, regardless of which the Pd atoms are the surficial or interior ones. Therefore, we neglected the small fraction of Pd atoms that are catalytically inactivated by outermost layers. Further, examinations indicated that the higher amount of the catalyst $(10 \mathrm{mg})$ does not have significant effect on the improvement of the catalytic activity from viewpoint of TON. It is noteworthy that the lower loadings and higher loading of $\mathrm{Pd}(=0.5 \mathrm{wt} \%$ and $3 \mathrm{wt} \%)$ on MO-ISO did not have promising catalytic results since the TON of the reaction were obtained lower than that of $2 \mathrm{wt} \%$-loading $\mathrm{Pd}$ nanoparticles. This observation indicates that the TON value is optimal at $2 \mathrm{wt} \%$ of loaded $\mathrm{Pd}$ in MO-ISO for the reduction of $p$-nitrophenol. In addition, we examined the reduction reaction within $20 \mathrm{~min}$ while sampling in every $5 \mathrm{~min}$. We realised that the major fraction of the reaction progress occurs at early $10 \mathrm{~min}$. We confirmed the conversion of PNP to PAP by observing fading of an adsorption peak at $410 \mathrm{~nm}$ and appearance of a related peak at $317 \mathrm{~nm}$ over the reaction time (Figure 6).
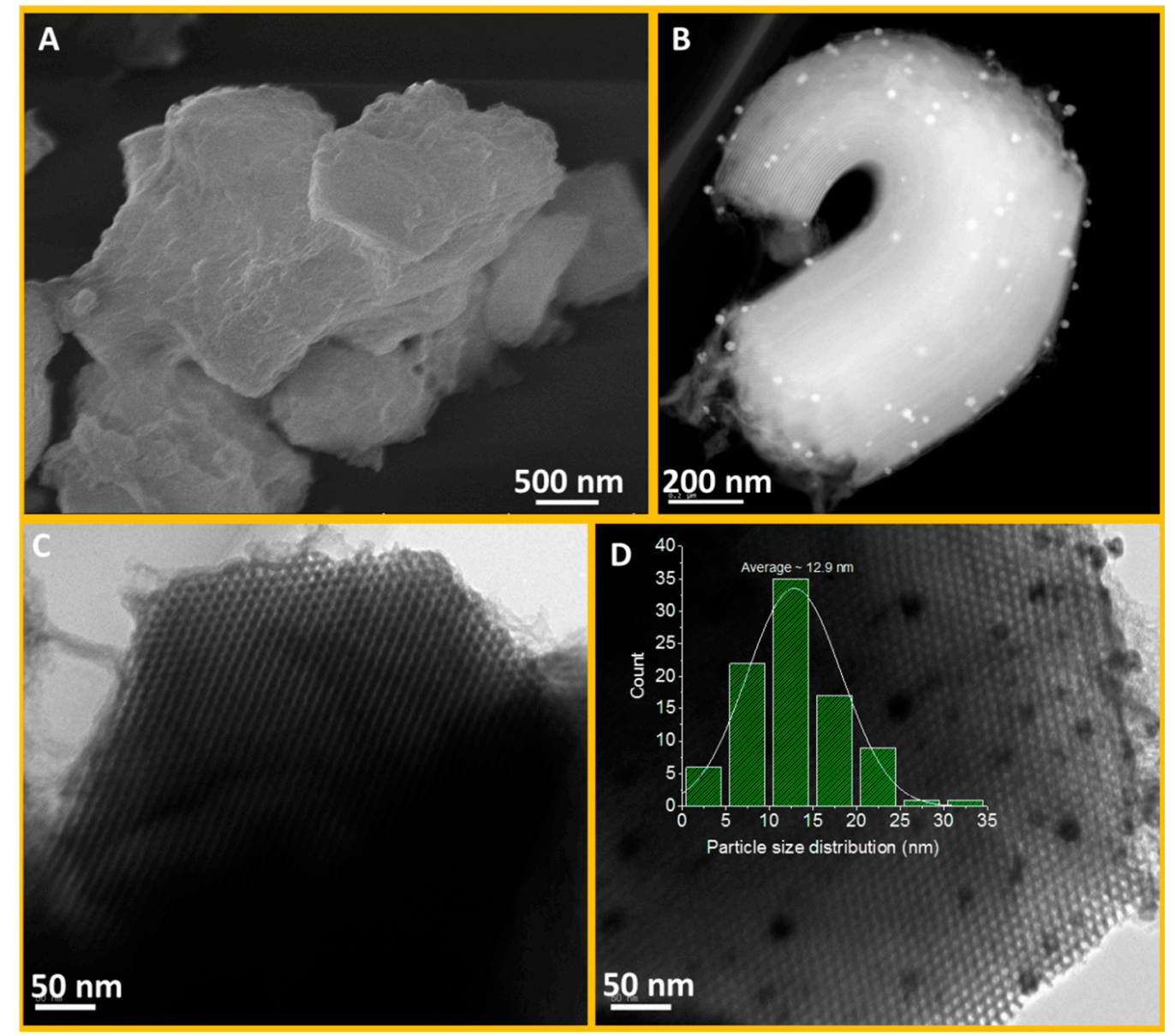

Figure 4. (A) SEM and (B) HAADF-STEM images of Pd@MO-ISO. TEM images of (C) MO-ISO and (D) Pd@MO-ISO. Inset indicates the pore size distribution of Pd nanoparticles measured by HAADF-STEM and TEM images. 

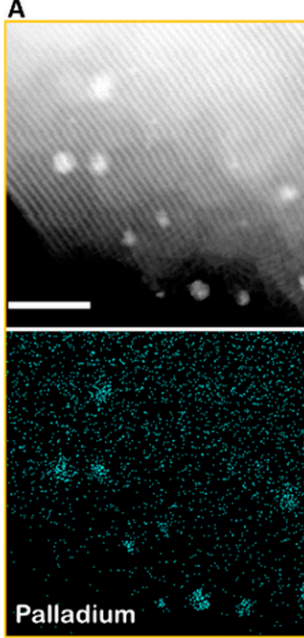
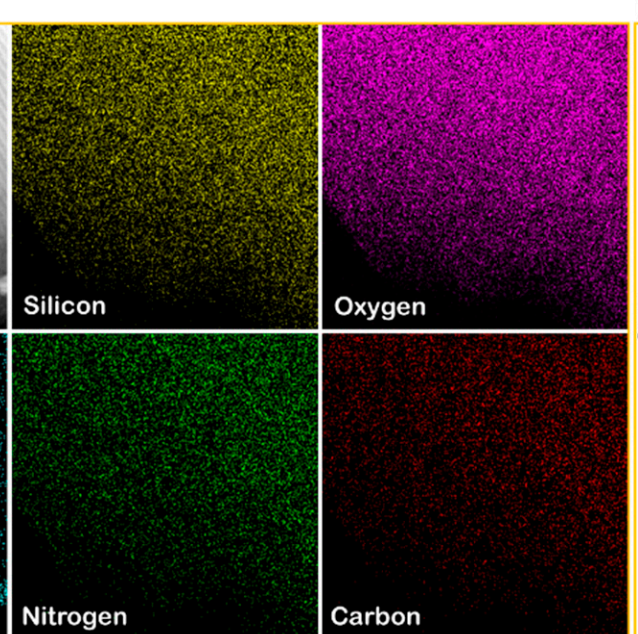

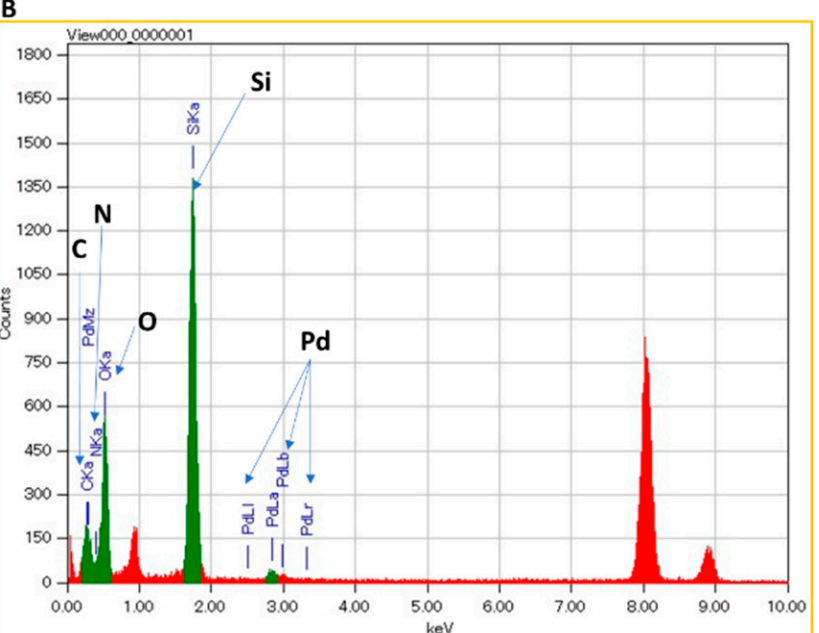

Figure 5. (A) HAADF-STEM image and elemental TEM-mapping images of every element in a separate image related to Pd@MO-ISO. Scale bar shows 100 nm and is constant for all images. (B) TEM-EDS spectra of Pd@MO-ISO.

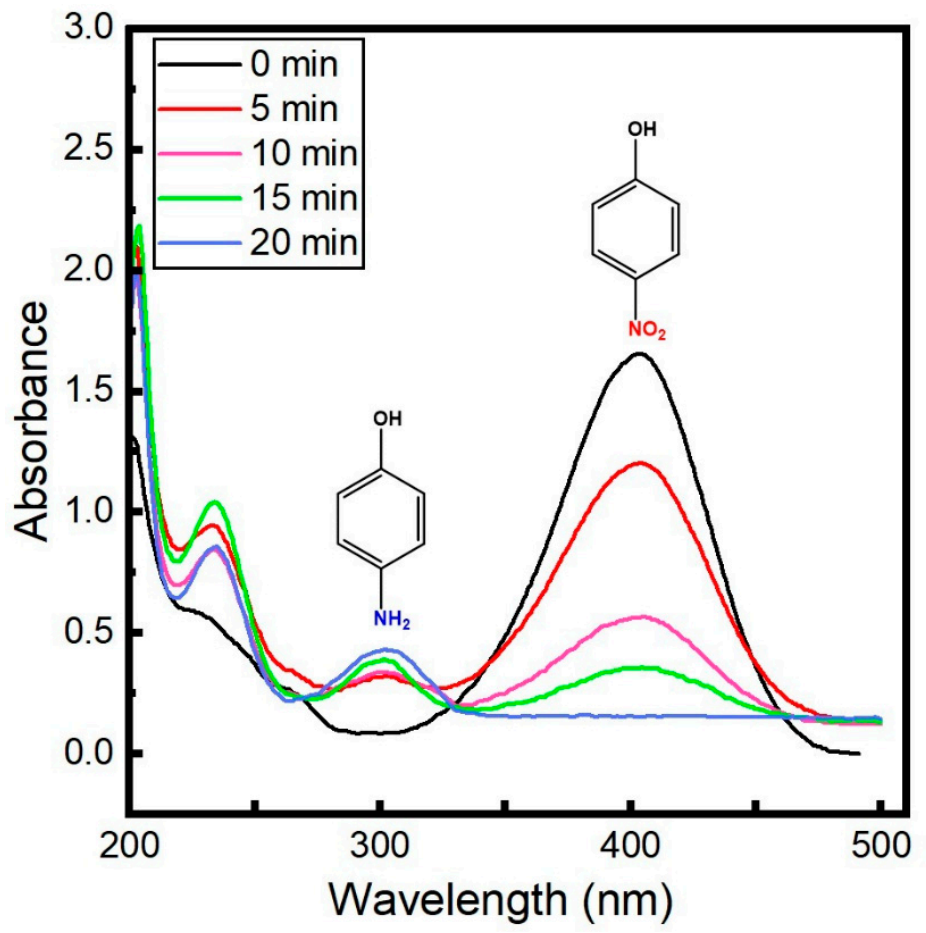

Figure 6. Scanning the UV-Visible spectra of PNP solution that catalytically reduces to PAP within $20 \mathrm{~min}$.

We also studied the recyclability of the catalyst, Pd@MO-ISO, as the recyclability is one of the pivotal features in heterogeneous catalysts in organic transformation. Accordingly, we used the optimised reaction conditions, i.e., $3 \mathrm{mM}$ PNP, room temperature, aqueous conditions, and $5 \mathrm{mmol} \mathrm{NaBH}_{4}$. The results show that Pd@MO-ISO as a heterogeneous catalyst that is easily recoverable and reusable at least for five consecutive cycles (Figure 7A). In addition, the analysis of the reaction solution, once the catalyst is filtered, through atomic absorption spectroscopy (AAS) in the fifth cycle, confirmed that the Pd leaching is negligible $(<1 \%)$. SEM-based EDS spectra of recovered Pd@MO-ISO after five cycles also shows the presence of Pd species, further confirming the resistance of the material in Pd leaching (Figure 7B). However, the observed loss, could be attributed to the relative collapse of the silica mesoscopic structure by exposing to the highly reactive $\mathrm{NaBH}_{4}$. 

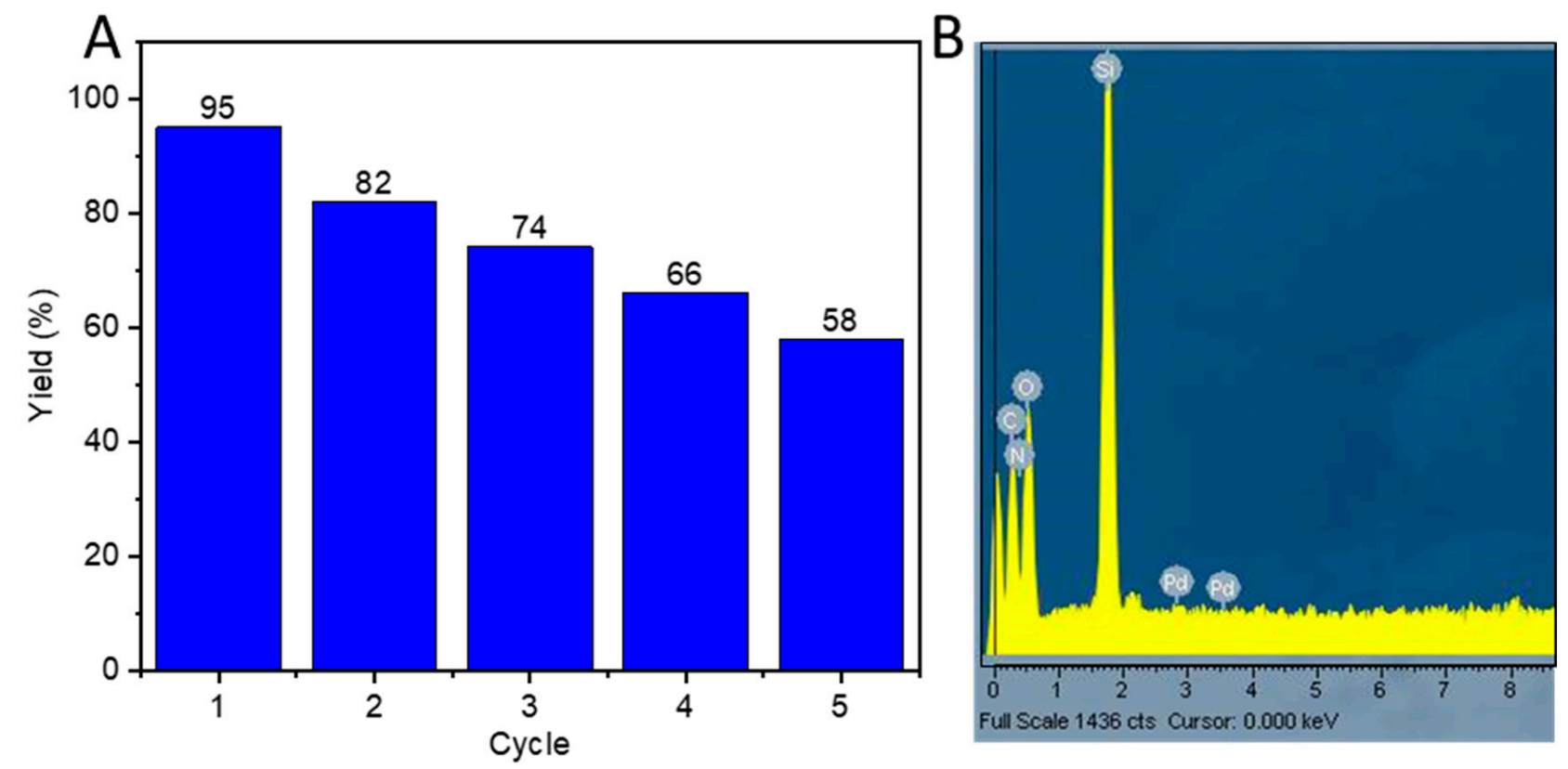

Figure 7. (A) Recyclability of the Pd@MO-ISO as catalyst in the chemical reduction of PNP into PAP in five consecutive cycles. (B) EDS spectra of PD@MO-ISO.

We further compared the catalytic results of our catalyst and method with the previously reported catalysts, which are used for PNP reduction to PAP. We found our catalyst superior to those of several catalysts and methods reported before, in terms of TON (Table 1).

Table 1. Comparing the PNP reduction through our synthesised catalyst with the previously reported catalysts in aqueous solution in the presence of $\mathrm{NaBH}_{4}$ as reducing agent.

\begin{tabular}{ccccc}
\hline Catalyst & Time (min) & Temperature $\left({ }^{\circ} \mathbf{C}\right)$ & TON & Reference \\
\hline TA@Fe $\mathrm{O}_{4}$-AgNPs & 6 & r.t. ${ }^{*}$ & 25 & {$[44]$} \\
PdPt@Chitosan & 120 & 22 & 10 & {$[45]$} \\
Pd@MO-urea & 26 & r.t. & 64 & {$[17]$} \\
Pd@MO-ISO & 20 & r.t. & 125 & This work \\
\hline${ }^{*}$ r.t. is room temperature. & & &
\end{tabular}

\section{Materials and Methods}

\subsection{Materials Characterisations}

The SEM images were observed with a HITACHI SU-8230 scanning SEM. TEM images were taken with a JEOL JEM-2100F microscope (operated at $300 \mathrm{kV}$ ). $\mathrm{N}_{2}$ adsorptiondesorption, BJH, and BET analyses were carried out at $77 \mathrm{~K}$ using a Microtrac Bel BEL-mini. Prior to the measurements, the samples were evacuated at $90{ }^{\circ} \mathrm{C}$ for $20-24 \mathrm{~h}$. ICP-OES was performed by Pekin-Elmer (Waltham, MA, USA) model. The pore size distribution of the mesopores were determined by BJH analysis obtained by Autosorb Microtrac Bel BEL-mini.

\subsection{Materials Synthesis}

For the synthesis of this organosiloxane bridge, THEIC ( $3 \mathrm{mmol}, 0.783 \mathrm{~g})$ was reacted with (3-isocyanatopropyl) triethoxysilane $(1 \mathrm{mmol}, 0.5 \mathrm{~mL})$ at $135{ }^{\circ} \mathrm{C}$ for $3 \mathrm{~h}$, cooled to $80^{\circ} \mathrm{C}$, and stirred at that temperature for another $3 \mathrm{~h}$. Then, a colourless oily product was obtained at the end, which was used without further purifications [16]. The synthesised isocyanurate-based organosiloxane bridge was further employed in the synthesis of the corresponding MO through co-condensation of TEOS. Accordingly, the Pluronic triblock copolymer P123 (2 g, MW $\left.=5800 \mathrm{~g} \cdot \mathrm{mol}^{-1}\right)$ was dissolved in $\mathrm{HCl}$ aqueous solution $\left(10^{-4} \mathrm{M}\right.$, 
$75 \mathrm{~mL}$ ) and stirred for $3 \mathrm{~h}$. Then, the as-synthesised organosiloxane bridge from the previous step was mixed with TEOS with the molar ratio of 1:15, respectively, and cocondensed in the $\mathrm{P} 123 / \mathrm{HCl}$ aqueous solution mixture and stirred for $24 \mathrm{~h}$ at $25^{\circ} \mathrm{C}$. After stirring for $24 \mathrm{~h}$, the reaction mixture was transferred to an autoclave for aging for $24 \mathrm{~h}$ at $100{ }^{\circ} \mathrm{C}$. After aging, the polymeric $\mathrm{P} 123$ was extracted from the pore space by Soxhlet with $\mathrm{MeOH}$ for 4 days. A white powder as the final product after drying at $60{ }^{\circ} \mathrm{C}$ for $4 \mathrm{~h}$ in an oven was obtained. For simplicity, the product obtained in this stage was named "MO-ISO."

$\mathrm{Na}_{2} \mathrm{PdCl}_{4}(37 \mu \mathrm{mol}, 0.011 \mathrm{~g})$ in acetonitrile was added dropwise to MO-ISO $(0.2 \mathrm{~g})$. Afterward, creamy pasty product was collected and dried at $100{ }^{\circ} \mathrm{C}$. After drying for $3 \mathrm{~h}$, it was re-dispersed in $\mathrm{MeOH}$ and then, $\mathrm{NaBH}_{4}$ was added to the dispersion and allowed to stir for $0.5 \mathrm{~h}$. Finally, the final product was centrifuged and washed for three times with $\mathrm{EtOH}(10 \mathrm{~mL})$ and dried in oven at $60^{\circ} \mathrm{C}$ for $3 \mathrm{~h}$. For simplicity, the product obtained in this step was named "Pd@MO-ISO." The wt $\%$ of Pd loaded in MO-ISO was analysed by ICP-OES technique, indicating that the Pd content is $2 \mathrm{wt} \%$ in the MO-ISO.

\subsection{Catalytic Test}

In the catalytic test to reduce PNP to PAP, Pd@MO-ISO (5 mg) was dispersed in the aqueous PNP solution ( $3 \mathrm{mM}, 40 \mathrm{~mL}$ ) by sonicating for $5 \mathrm{~min}$. Then, the sodium borohydride ( $5 \mathrm{mmol}, 125 \mathrm{mg}$ ) was added to the solution and continued to stir vigorously. During the reaction, every $5 \mathrm{~min}$, the sampling from reaction progress was achieved by a syringe equipped with syringe filter to separate the catalyst from the reaction media. Then, the obtained samples from each minute were analysed by UV-VIS spectrometer to monitor the reaction progress.

\section{Conclusions}

Here, we presented a heterogeneous green catalyst on the basis of the new Pd-based hybrid mesoporous organosilica, which could successfully adsorb Pd ions and support it on the surface. The Pd supporting process had not a significant destructive effect on the mesoscopic structure of the MO-ISO and had an efficient catalytic activity in the chemical reduction of PNP to PAP via $\mathrm{NaBH}_{4}$ as reducing agent. The catalyst also showed a high rate of recyclability and negligible Pd species leaching over recycling the catalyst. The catalytic activity of Pd@MO-ISO was excellent in comparison to other previously reported catalysts with the similar textural structure.

Author Contributions: Conceptualization, E.D. and M.G.D.; methodology, A.Z.; software, A.Z.; validation, E.D., A.Z.; formal analysis, A.Z.; investigation, A.Z.; resources, M.G.D.; data curation, A.Z.; writing-original draft preparation, A.Z.; writing-review and editing, E.D. and M.G.D.; visualization, A.Z.; supervision, M.G.D. and E.D.; project administration, M.G.D. and E.D. All authors have read and agreed to the published version of the manuscript.

Funding: This research received no external funding.

Conflicts of Interest: The authors declare no conflict of interest.

\section{References}

1. Asefa, T.; MacLachlan, M.J.; Coombs, N.; Ozin, G.A. Periodic mesoporous organosilicas with organic groups inside the channel walls. Nature 1999, 402, 867-871. [CrossRef]

2. Inagaki, S.; Guan, S.; Fukushima, Y.; Ohsuna, T.; Terasaki, O. Novel mesoporous materials with a uniform distribution of organic groups and inorganic oxide in their frameworks. J. Am. Chem. Soc. 1999, 121, 9611-9614. [CrossRef]

3. Melde, B.J.; Holland, B.T.; Blanford, C.F.; Stein, A. Mesoporous sieves with unified hybrid inorganic/organic frameworks. Chem. Mater. 1999, 11, 3302-3308. [CrossRef]

4. Doustkhah, E.; Mohtasham, H.; Hasani, M.; Ide, Y.; Rostamnia, S.; Tsunoji, N.; Hussein, N.; Assadi, M. Merging periodic mesoporous organosilica (PMO) with mesoporous aluminosilica (Al/Si-PMO): A catalyst for green oxidation. Mol. Catal. 2020, 482, 110676. [CrossRef]

5. Doustkhah, E.; Tahawy, R.; Simon, U.; Tsunoji, N.; Ide, Y.; Hanaor, D.A.H.; Assadi, M.H.N. Bispropylurea bridged polysilsesquioxane: A microporous MOF-like material for molecular recognition. Chemosphere 2021, 276, 130181. [CrossRef] [PubMed] 
6. Esmat, M.; Mohtasham, H.; GadelHak, Y.; Mehrebani, R.T.; Tahawy, R.; Rostamnia, S.; Fukata, N.; Khaksar, S.; Doustkhah, E.J.C. 2D Mesoporous Channels of PMO; a Platform for Cluster-Like Pt Synthesis and Catalytic Activity in Nitrophenol Reduction. Catalysts 2020, 10, 167. [CrossRef]

7. Elhamifar, D.; Yari, O.; Karimi, B. Highly ordered mesoporous organosilica-titania with ionic liquid framework as very efficient nanocatalyst for green oxidation of alcohols. J. Colloid Interface Sci. 2017, 500, 212-219. [CrossRef] [PubMed]

8. Mousavi, K.Z.; Yamini, Y.; Karimi, B.; Seidi, S.; Khorasani, M.; Ghaemmaghami, M.; Vali, H. Imidazolium-based mesoporous organosilicas with bridging organic groups for microextraction by packed sorbent of phenoxy acid herbicides, polycyclic aromatic hydrocarbons and chlorophenols. Microchim. Acta 2019, 186, 239. [CrossRef]

9. Chandra, D.; Das, S.K.; Bhaumik, A. A fluorophore grafted 2D-hexagonal mesoporous organosilica: Excellent ion-exchanger for the removal of heavy metal ions from wastewater. Microporous Mesoporous Mater. 2010, 128, 34-40. [CrossRef]

10. Kim, Y.; Lee, J. Advanced molecular recognition of 3-nitro-L-tyrosine: The use of zwitterion embedded molecularly imprinted mesoporous organosilica with sub-nanomolar sensitivity. Biosens. Bioelectron. 2020, 160, 112216. [CrossRef]

11. Yamanaka, K.-I.; Maegawa, Y.; Yamada, Y.; Inagaki, S. Excited-State Dynamics of 2,2'-Bipyridine Moieties Embedded in the Framework of Periodic Mesoporous Organosilica. J. Phys. Chem. C 2019, 123, 28443-28449. [CrossRef]

12. Kaczmarek, A.M.; Maegawa, Y.; Abalymov, A.; Skirtach, A.G.; Inagaki, S.; Van Der Voort, P. Lanthanide-Grafted Bipyridine Periodic Mesoporous Organosilicas (BPy-PMOs) for Physiological Range and Wide Temperature Range Luminescence Thermometry. ACS Appl. Mater. Interfaces 2020, 12, 13540-13550. [CrossRef] [PubMed]

13. Etienne, M.; Goux, A.; Sibottier, E.; Walcarius, A.J. Oriented mesoporous organosilica films on electrode: A new class of nanomaterials for sensing. J. Nanosci. Nanotechnol. 2009, 9, 2398-2406. [CrossRef] [PubMed]

14. Matsukawa, H.; Yoshida, M.; Tsunenari, T.; Nozawa, S.; Sato-Tomita, A.; Maegawa, Y.; Inagaki, S.; Kobayashi, A.; Kato, M. Fast and stable vapochromic response induced through nanocrystal formation of a luminescent platinum(II) complex on periodic mesoporous organosilica. Sci. Rep. 2019, 9, 15151. [CrossRef] [PubMed]

15. Wei, Y.; Li, X.; Zhang, R.; Liu, Y.; Wang, W.; Ling, Y.; El-Toni, A.M.; Zhao, D. Periodic Mesoporous Organosilica Nanocubes with Ultrahigh Surface Areas for Efficient $\mathrm{CO}_{2}$ Adsorption. Sci. Rep. 2016, 6, 20769. [CrossRef] [PubMed]

16. Zebardasti, A.; Dekamin, M.G.; Doustkhah, E.; Assadi, M.H.N. Carbamate-Isocyanurate-Bridged Periodic Mesoporous Organosilica for van der Waals $\mathrm{CO}_{2}$ Capture. Inorg. Chem. 2020, 59, 11223-11227. [CrossRef] [PubMed]

17. Doustkhah, E.; Mohtasham, H.; Farajzadeh, M.; Rostamnia, S.; Wang, Y.; Arandiyan, H.; Assadi, N.H.M. Organosiloxane tunability in mesoporous organosilica and punctuated Pd nanoparticles growth; theory and experiment. Microporous Mesoporous Mater. 2020, 293, 109832. [CrossRef]

18. Hunks, W.J.; Ozin, G.A. Challenges and advances in the chemistry of periodic mesoporous organosilicas (PMOs). J. Mater. Chem. 2005, 15, 3716-3724. [CrossRef]

19. Doustkhah, E.; Hassandoost, R.; Khataee, A.; Luque, R.; Assadi, M.H.N. Hard-templated metal-organic frameworks for advanced applications. Chem. Soc. Rev. 2021, 50, 2927-2953. [CrossRef] [PubMed]

20. Doustkhah, E.; Rostamnia, S.; Imura, M.; Ide, Y.; Mohammadi, S.; Hyland, C.J.T.; You, J.; Tsunoji, N.; Zeynizadeh, B.; Yamauchi, Y. Thiourea bridged periodic mesoporous organosilica with ultra-small Pd nanoparticles for coupling reactions. RSC Adv. 2017, 7, 56306-56310. [CrossRef]

21. Doustkhah, E.; Rostamnia, S.; Zeynizadeh, B.; Kim, J.; Yamauchi, Y.; Ide, Y. Efficient $\mathrm{H}_{2}$ Generation Using Thiourea-based Periodic Mesoporous Organosilica with Pd Nanoparticles. Chem. Lett. 2018, 47, 1243-1245. [CrossRef]

22. Rostamnia, S.; Doustkhah, E.; Bulgar, R.; Zeynizadeh, B. Supported palladium ions inside periodic mesoporous organosilica with ionic liquid framework (Pd@IL-PMO) as an efficient green catalyst for S-arylation coupling. Microporous Mesoporous Mater. 2016, 225, 272-279. [CrossRef]

23. Dekamin, M.G.; Arefi, E.; Yaghoubi, A. Isocyanurate-based periodic mesoporous organosilica (MO-ICS): A highly efficient and recoverable nanocatalyst for the one-pot synthesis of substituted imidazoles and benzimidazoles. RSC Adv. 2016, 6, 86982-86988. [CrossRef]

24. Haghighat, M.; Shirini, F.; Golshekan, M. Synthesis of tetrahydrobenzo[b]pyran and Pyrano $[2,3-d]$ pyrimidinone derivatives using $\mathrm{Fe}_{3} \mathrm{O}_{4} @ \mathrm{Ph}-\mathrm{MO}-\mathrm{NaHSO}_{4}$ as a new magnetically separable nanocatalyst. J. Nanosci. Nanotechnol. 2019, 19, 3447-3458. [CrossRef] [PubMed]

25. Yaghoubi, A.; Dekamin, M.G.; Arefi, E.; Karimi, B. Propylsulfonic acid-anchored isocyanurate-based periodic mesoporous organosilica (PMO-ICS-Pr-SO ${ }_{3} \mathrm{H}$ ): A new and highly efficient recoverable nanoporous catalyst for the one-pot synthesis of bis(indolyl)methane derivatives. J. Colloid Interface Sci. 2017, 505, 956-963. [CrossRef] [PubMed]

26. Su, L.; Ma, J.; Wang, J.; Jiang, W.; Zhang, W.-X.; Yang, J. Site-selective exposure of iron nanoparticles to achieve rapid interface enrichment for heavy metals. Chem. Commun. 2020, 56, 2795-2798. [CrossRef] [PubMed]

27. Waki, M.; Mizoshita, N.; Ohsuna, T.; Tani, T.; Inagaki, S. Crystal-like periodic mesoporous organosilica bearing pyridine units within the framework. Chem. Commun. 2010, 46, 8163-8165. [CrossRef]

28. Zou, H.; Wang, R.; Dai, J.; Wang, Y.; Wang, X.; Zhang, Z.; Qiu, S. Amphiphilic hollow porous shell encapsulated Au@Pd bimetal nanoparticles for aerobic oxidation of alcohols in water. Chem. Commun. 2015, 51, 14601-14604. [CrossRef]

29. Attia, M.F.; Swasy, M.I.; Ateia, M.; Alexis, F.; Whitehead, D.C. Periodic mesoporous organosilica nanomaterials for rapid capture of VOCs. Chem. Commun. 2020, 56, 607-610. [CrossRef] 
30. Rostamnia, S.; Doustkhah, E. Nanoporous silica-supported organocatalyst: A heterogeneous and green hybrid catalyst for organic transformations. RSC Adv. 2014, 4, 28238-28248. [CrossRef]

31. Esquivel, D.; Amaro-Gahete, J.; Caballero-Casero, N.; Jiménez-Sanchidrián, C.; Ruiz, J.R.; Rubio, S.; Van Der Voort, P.; RomeroSalguero, F.J. Tailoring Bifunctional Periodic Mesoporous Organosilicas for Cooperative Catalysis. ACS Appl. Nano Mater. 2020, 3 , 2373-2382. [CrossRef]

32. Zarei, M.; Zolfigol, M.A.; Moosavi-Zare, A.R.; Noroozizadeh, E.; Rostamnia, S. Three-Component Synthesis of Spiropyrans Using SBA-15/En Bonded Phosphorous Acid [SBA-15/ $\mathrm{Pr}_{-\mathrm{NH}}\left(\mathrm{CH}_{2} \mathrm{PO}_{3} \mathrm{H}_{2}\right)_{\mathrm{y}}-\mathrm{Et}-\mathrm{NH}_{2-\mathrm{x}}\left(\mathrm{CH}_{2} \mathrm{PO}_{3} \mathrm{H}_{2}\right)_{\mathrm{x}}$ ] as a New Nanoporous Heterogeneous Catalyst. ChemistrySelect 2018, 3, 12144-12149. [CrossRef]

33. Zhao, D.; Feng, J.; Huo, Q.; Melosh, N.; Fredrickson, G.H.; Chmelka, B.F.; Stucky, G.D. Triblock Copolymer Syntheses of Mesoporous Silica with Periodic 50 to 300 Angstrom Pores. Science 1998, 279, 548-552. [CrossRef] [PubMed]

34. Kruk, M.; Jaroniec, M.; Ko, C.H.; Ryoo, R. Characterization of the Porous Structure of SBA-15. Chem. Mater. 2000, 12, 1961-1968. [CrossRef]

35. Narani, A.; Reddy Kannapu, H.P.; Natte, K.; Burri, D.R. Pd-Nanoparticles immobilized organo-functionalized SBA-15: An efficient heterogeneous catalyst for selective hydrogenation of CC double bonds of $\alpha, \beta$-unsaturated carbonyl compounds. Mol. Catal. 2020, 497, 111200. [CrossRef]

36. Yu, Y.; Li, F.; Zang, Z.; Xu, L.; Liu, G. Highly efficient selective oxidation of 2-methylnaphthalene to vitamin K3 over mesoporous Al/Ti-SBA-15 catalysts: The effect of acid sites and textural property. Mol. Catal. 2020, 495, 111158. [CrossRef]

37. Yang, X.; Niu, L.; Xia, Z.; Yan, X.; Bai, G. Preparation of $\mathrm{Ni} / \mathrm{mSiO}_{2}$ with the existence of hydrogelator: Insight into hydrogelator self-assembly on metal dispersion and catalytic performance in quinoline hydrogenation. Mol. Catal. 2020, 493, 111094. [CrossRef]

38. Szabó, B.; Novodárszki, G.; May, Z.; Valyon, J.; Hancsók, J.; Barthos, R. Conversion of ethanol to butadiene over mesoporous $\mathrm{In}_{2} \mathrm{O}_{3}$-promoted $\mathrm{MgO}-\mathrm{SiO}_{2}$ catalysts. Mol. Catal. 2020, 491, 110984. [CrossRef]

39. Shimizu, M.; Michikawa, K.; Maegawa, Y.; Inagaki, S.; Fujita, K.-I. Iridium Complex Immobilized on Custom-Designed Periodic Mesoporous Organosilica as Reusable Catalyst for the Dehydrogenative Oxidation of Alcohols. Acs Appl. Nano Mater. 2020, 3 , 2527-2535. [CrossRef]

40. Aalinejad, M.; Pesyan, N.N.; Doustkhah, E. Diaza crown-type macromocycle (kryptofix 22) functionalised carbon nanotube for efficient $\mathrm{Ni}^{2+}$ loading; A unique catalyst for cross-coupling reactions. Mol. Catal. 2020, 494, 111117. [CrossRef]

41. Ahadi, A.; Rostamnia, S.; Panahi, P.; Wilson, L.D.; Kong, Q.; An, Z.; Shokouhimehr, M. Palladium Comprising Dicationic Bipyridinium Supported Periodic Mesoporous Organosilica (PMO): Pd@Bipy-PMO as an Efficient Hybrid Catalyst for SuzukiMiyaura Cross-Coupling Reaction in Water. Catalysts 2019, 9, 140. [CrossRef]

42. Rostamnia, S.; Doustkhah, E.; Karimi, Z.; Amini, S.; Luque, R. Surfactant-Exfoliated Highly Dispersive Pd-Supported Graphene Oxide Nanocomposite as a Catalyst for Aerobic Aqueous Oxidations of Alcohols. ChemCatChem 2015, 7, 1678-1683. [CrossRef]

43. Liu, C.; Tan, R.; Yu, N.; Yin, D. Pt-Pd bi-metal nanoparticles captured and stabilized by imine groups in a periodic mesoporous organosilica of SBA-15 for hydrogenation of nitrobenzene. Microporous Mesoporous Mater. 2010, 131, 162-169. [CrossRef]

44. Sangili, A.; Annalakshmi, M.; Chen, S.-M.; Balasubramanian, P.; Sundrarajan, M. Synthesis of silver nanoparticles decorated on core-shell structured tannic acid-coated iron oxide nanospheres for excellent electrochemical detection and efficient catalytic reduction of hazardous 4-nitrophenol. Compos. B Eng. 2019, 162, 33-42. [CrossRef]

45. Berillo, D.; Cundy, A. 3D-macroporous chitosan-based scaffolds with in situ formed Pd and Pt nanoparticles for nitrophenol reduction. Carbohydr. Polym. 2018, 192, 166-175. [CrossRef] [PubMed] 